\title{
Correction to: A Novel Model for Stock Price Prediction Using Hybrid Neural Network
}

\author{
Sumanjit Das $^{1} \cdot$ Sarojananda Mishra $^{2} \cdot$ Manas Ranjan Senapati $^{3}$
}

Published online: 13 August 2019

(C) The Institution of Engineers (India) 2019

\section{Correction to: J. Inst. Eng. India Ser. B}

(December 2018) 99(6):555-563

https://doi.org/10.1007/s40031-018-0343-7

In the original publication of an article, the order of author names and the affiliation of Dr. Sumanjit Das were incorrect. Now the correct order and affiliation have been published in this correction.
Publisher's Note Springer Nature remains neutral with regard to jurisdictional claims in published maps and institutional affiliations.

The original article can be found online at https://doi.org/10.1007/ s40031-018-0343-7.

Manas Ranjan Senapati

manassena@gmail.com

1 Department of Computer Science and Engineering, Biju

Patnaik University of Technology, Rourkela, Odisha 769004, India

2 Department of Computer Science and Engineering, Indira Gandhi Institute of Technology, Dhenkanal, Odisha 759146, India

3 Department of Information Technology, Veer Surendra Sai University of Technology, Sambalpur, Odisha 768018, India 